too briefly in the early part of Leonard Bell's essay. Quite possibly, given space and encouragement, he could have written an overall interpretative essay which would have given a context for these diverse phenomena. Surely one could expect something of that kind from a book emerging from a university department (and, at that, a German department) and published by a venerable university press.
But, not to end too negatively, the book has a great value as a portrait gallery of a group of people who for the most part would not have been New Zealanders except for the less admirable characteristics of 'Germanness' which drove them to this country, to our great gain. Readers should compile their own roll-call of culture-heroes - mine would include, not in any special order, Paul Hoffmann, Karl Popper,
Peter Munz, Ernst Plischke, Erich Geiringer, Maria Dronke, Frank Hofmann, Peter Jacoby, Wolfgang Rosenberg (whose father-in-law, Siegfried Eichelbaum, could have had more than a mere mention) and - though not finding a place here the political scientist Helmut Pappe, the administrator Paul Heller, and the historian Herbert Roth. W.H. OLIVER is Emeritus Professor of History at Massey University.

\title{
New Zealand Politics and Social Patterns: Selected works by Robert Chapman
}

\section{Elizabeth McLeay (ed), Victoria University Press, 1999}

\begin{abstract}
Obsolescence is perhaps more marked due to their politicalscience focus, which pays little or no attention to perennially important ideological, cultural, or historical factors (apart from one or two tentative references to Tocqeville), while stressing many inevitably ephemeral elements such as opinion polls, manifestos, elections and administrative minutiae.
\end{abstract}

$\mathrm{T}$ HUS ROBERT TOMBS IN THE Times Literary Supplement ('The Unhealed Fracture', 25 April 1997, p. 7) reviewing several books about Chirac's ascendancy to the French presidency. His opinion provided some warning lights before I began reading Elizabeth McLeay's collection of writings selected from Robert Chapman's four decades of commentary on the New Zealand scene. After all, Chapman was for most of his academic career (from 1964 to 1988) a
Professor of Political Studies at Auckland University; he had pioneered election studies and political polling in this country. How would his detailed observations on the 'ephemera' of elections as far back as 1928 stand up in the ahistorical 1990s? Indeed (although this is a question presumably implicitly answered by the publisher), was there an audience for this work?

The short answer to these questions is 'yes' and 'there ought to be'.

Nerw Zealand Politics and Social Patterns is a rich work: rich in the diversity of topics covered; rich in insights; rich in language. This is not a book to be digested at one sitting. You may wish to set aside the time to get inside one of the three Parts into which the editor has divided the collection: Part One-Society and Politics; Part Two-Town, City and Country; and Part Three - Governing Democratically. Or, as I did, you may want to take the essays one at a time (especially if your memory extends back to particular elections) and call back the associations of now-forgotten, but at the time critical, political events.

The first article 'Fiction and the Social Pattern: Some Implications of Recent New Zealand Writing' is an extended version of an address to a Students Association Congress in 1952 and first published in Landfall. It serves to remind us of Chapman's literary contribution as a poet, editor (the 1956 Oxford Anthology of New Zealand Verse) and critic. I cannot comment on the impact of this review piece when it appeared, nor on the assessment nearly fifty years later of Chapman's judgments. Elizabeth McLeay tells us that it is 'widely regarded as a seminal work on New Zealand literature and society'. Certainly, the discussion of 'elements in the national scene' provides a wealth of intriguing observation both historical and contemporary about New Zealand society.

For the historian Part Two is the 
rich lode to be explored. After an introductory 1963 piece (from the University of Auckland Gazette) on 'Psephology' (derived from the Greeks' custom of dropping a pebble ( $p$ sephos) into an urn at an election McLeay has assembled articles on the general elections of 1928 ("The Sad, Slow End of the Twenties'), 1963 ('The 'No Change' Election', 1969 , 1975, 1978 ('The Case of the Pulled Punch'), and 1981 '(New Zealand Defers Decision'). Most of these articles were immediate reflections, for example, radio commentaries on the day after the election. To complete the picture it would have been good to have had Chapman's reactions to the Kirk triumph of 1972 and the Lange 'revolution' of 1984.

The Chapman approach to electoral studies is developed well in the 1963 chapter 'The Response to Labour and the Question of Parallelism of Opinion, 1928-1960'). He dissects 'the cadaver on the bench' (Chapman is fond of metaphors) - public opinion as recorded at elections - and attempts to answer the question:

did changes of political preference in the various sections ... of the body politic [large town, marginal city, rural, richer city, farmer] happen at the same time and did they take the same general direction. Or did an alteration in one section tend to cancel out an opposite movement in another ... ? (p132)

If the former, then a degree of 'parallelism' could be asserted; the lesson for the political parties would be that platforms targeted at sectional appeal 'would represent a problematical gain, difficult to achieve and not worth the attendant repercussions' (p133). Between 1928 and 1960 there was, in Chapman's view, a parallelism of opinion 'arriving at national and nearly unanimous judgments of governmental performance, while expressing in sectional distancing the varied assessment of parties held by the various kinds of electorates' (p160). By 1981 'deep and inflamed divisions' and an 'abnormal rift between marginal mixed city and marginal town' had interrupted the course of 'parallelism' and 'only increasingly common economic and social experiences ... will bring the two back together again and produce the increasingly common verdicts and positive choices which New Zealand society and government require' (p224). This would provide an apt text for an exploration of the events of the past two decades. We do not have this from Chapman in this book. We do, however, have a stimulating 1994 analysis of the Lange/Douglas conflict of 1987/88 set within 'A Political Culture Under Pressure: The Struggle to Preserve a progressive Tax base for Welfare and the Positive State'. There are lessons still for the conduct of government business as well as the values at stake.

Chapman is not a supporter of proportional representation. 'To put forward PR as a likely New Zealand option for the eighties is therefore to run the danger of creating a massive diversion from more practicable options' (p286 from a 1979 essay). He advances a strong case for the single member constituency, first past the post electoral system.
Two further chapters cry out for mention. 'The Politics of Division', first published in 1983, provides in my judgment the fairest summing up of the Muldoon style of politics that we are likely to get until Barry Gustafson's much-awaited biography appears. And 'Voting in the Maori Political Sub-system', originally prepared for the 1986 Royal Commission on the Electoral System', illuminates much current speculation. Chapman concludes his historical survey thus:

Maori voters have invented their own parties, adapted other people's parties and coalesced where it suited them. Maori voters display different policy priorities, values and party choices from those of the system in general. ... [Maori MPs] are supported by a political subsystem which has its own characteristics and uniqueness. (p255)

The warning lights flashed by Tombs in the quote with which I began this review were not really necessary. This is an historian's political scientist. The 'opinion polls, manifestos, elections and administrative minutiae' are swept up in a broad sweep of history and sociological observation. We are indebted to Elizabeth McLeay - the Introduction and notes are unobtrusively helpful - and Victoria University Press for bringing together the work of a man who has contributed in so many ways to the study and practice of politics in New Zealand.

JOHN R. MARTIN is Senior Lecturer in Public Policy in the School of Business and Public Management at Victoria University of Wellington. 